\title{
The Community Disease Prevention Behaviors in District Maros South Sulawesi Province
}

\author{
Herman $^{1}$, Gufran Darma Dirawan ${ }^{2}$, Muhammad Yahya $^{2} \&$ Mushawwir Taiyeb $^{2}$ \\ ${ }^{1}$ Politeknik Kesehatan Kemenkes, Makassar, Indonesia \\ ${ }^{2}$ Makassar State University, Makassar, Indonesia \\ Correspondence: Gufran Darma Dirawan, Makassar State University, Makassar, Indonesia. E-mail: \\ gufrandarma@yahoo.com
}

Received: May 13, 2015 Accepted: June 30, 2015 Online Published: October 28, 2015

doi:10.5539/ies.v8n11p104 URL: http://dx.doi.org/10.5539/ies.v8n11p104

\begin{abstract}
The community diseases prevention behaviors assumed influenced by knowledge of infectious disease, hygiene and health knowledge, motivation and of behaviors aof disese prevention than influence by attitude prevention of infectious diseases. This study aimed to examine the effect of variable knowledge infectious disease, hygiene and health knowledge, motivation prevention of infectious diseases, an attitude towards the behavior of infectious disease prevention. The research was conducted in Maros Regency, South Sulawesi Province with a quantitative approach survey method, which uses the quesioner that measure all variables mentioned above. The population in this study is the district's communities sampled from the Turikale, Mandai and Bantimurung sub-District of 200 respondents. The Structural Equational Modeling (SEM) is used to assess significant relation between all variable. The results showed that infectious disease prevention knowledge, attitudes prevention of infectious diseases affect the community behavior of infectious disease prevention, while knowledge of hygiene and health, communicable disease prevention motivation does not affect the behavior of infectious disease prevention. These results, suggest that knowledge of hygiene and health and prevention of infectious diseases motivation of concern that the incidence of infectious diseases, especially pulmonary tuberculosis, dengue fever, and diarrhea in Maros is not increased.
\end{abstract}

Keywords: behavior, knowledge, infectious diseases

\section{Introduction}

Efforts to achieve national development goals contained in the Act of 1945 has been carried out development in various fields of human life which, in the health sector that aims to raise awareness, willingness and ability to live a healthy life for every member of the community in order to obtain the optimal degree of public health through the creation of society, nation and state of Indonesia which is characterized by the behavior of people living healthy and in a healthy environment, have the ability to reach quality health services in a fair and equitable, and have optimal health status throughout the territory of the Republic of Indonesia (Law of Health, 2010).

Although the government, especially the Ministry of Health. has conducted various programs in the prevention of infectious diseases for the objectives mentioned above can be achieved, but the incidence of infectious diseases in Indonesia such as Tuberculosis (TB), Morbili, Dengue Hemorrhagic Fever (DHF), Hepatitis, HIV/AIDS, Malaria, Diarrhea, Fever typhoidal still high and can affect anyone (old, young, male, female, poor, or rich) and anywhere (Law of Health, 2010). In the province of South Sulawesi in 2010, the incidence of infectious diseases have been reported, among others, as many as 3,417 cases of pulmonary tuberculosis, diarrhea as many as 13494 cases (South Sulawesi Provincial Health Office, 2010), then in Maros the incidence of infectious diseases in 2011 by Survelans The disease has been reported that there are five types of diseases that the highest incidence of Tuberculosis as many as 633 cases, as many as 13242 cases of diarrhea, Similar Diseases Influenza (ILI) as many as 1115 cases, as many as 980 cases of abdominal typhoidal and Denque Dengue Fever (DHF) in the rainy season as well still high (District Health Office Maros, 2012).

Picture of the incidence of infectious diseases at the top, can be caused by various factors, among others, is the behavior. According Notoatmodjo (2007) that the transmission of infectious diseases depends on factors agent 
(disease-causing), host (landlady: including human behavior), and route of transmission (transmission path). Furthermore, according to the behavior of Bannet that action or individual action based on the knowledge, attitudes, and values espoused (Swan \& Stepp, 1974). Various studies on infectious diseases associated with behaviors have been reported, among others: the Media (2011) stated that the behavior and consciousness of some people to check their sputum and use of health care facilities are lacking. Nurjanah (2012) stated that the behavior of closed water reservoirs (TPA) and dispose of waste associated with the incidence of dengue, while the behavior of closed landfill and access to clean water is not associated with the incidence of dengue.

Based on the incidence of infectious diseases penjelan mentioned above, especially tuberculosis, diarrhea, and dengue fever in the province of South Sulawesi, especially in Maros. Researchers looked at the need to conduct research on the grounds that it is based on interviews with the Head of Observation and Control of Infectious Diseases Department of Health stated that the district's participation in the prevention of infectious diseases and concern for environmental sanitation house is still lacking. The next reason is still finding housing conditions that do not meet the standards as a healthy home in all districts with percentages between 20-40 per cent, this is caused by poverty, (Health Kab. Maros, 2012).

\section{Research Methods}

Type of research is a quantitative research, when viewed from the data collected, this study includes research survey, when viewed from the usefulness of this study, this research include descriptive and analytic studies, (Singarimnun, 1989). This research describes the behavior of the community in the prevention of infectious diseases while including reviewing analytic relationship between the independent variables (endogenous): "Knowledge prevention of infectious diseases" (X1), "Knowledge Clean and Healthy Lifestyle" (X2), "Motivation prevention of infectious diseases" (X3), on the dependent variable (Endogenous): "infectious disease prevention attitude" (X4), "Behavior community about prevention of infectious diseases" (Y).

Sample in this study is the people who live in villages or village that has a large 5 incidence of communicable diseases in the district's highest is suspected disease Pulmonary tuberculosis, diarrhea; Bloody diarrhea; ILI; Tipes abdominalis, and DBD (Health Kab. Maros, 2012). Sampling in this study is the multi-stage random sampling technique, with a sample of 200 respondents. Structural Equational Modeling (SEM) is used to assess the significan relationship between all variables.

Committed against people who visited the health center for the community wawacara techniques or sample who can not read and techniques for public inquiry or samples that can read using the instrument questionnaire containing questions about the independent variables: knowledge of infectious disease prevention, knowledge of health behavior, motivation penceghan infectious diseases, infectious disease prevention attitudes, and behavior of infectious disease prevention.

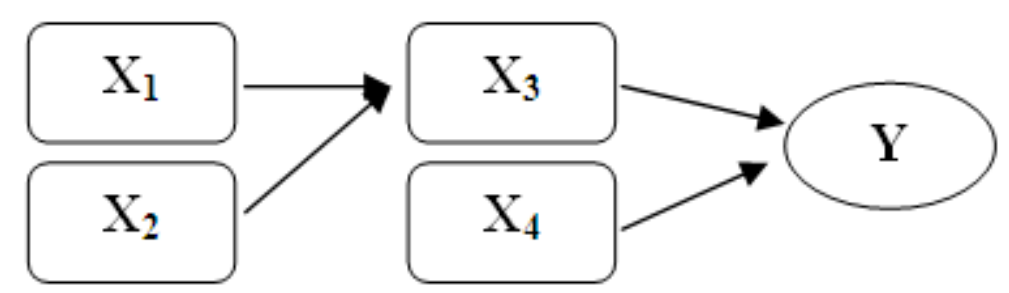

Figure 1. Research Design

$\mathrm{X}_{1}=$ Knowledge of Infectious diseases

$\mathrm{X}_{2}=$ Knowledge of clean and health lifestyle

$\mathrm{X}_{3}=$ Motivation prevention of infectious diseases

$\mathrm{X}_{4}=$ attitude prevention of infectious disease

$\mathrm{Y}=$ the community diseases prevention behavior

\section{Research Result}

3.1 Behavior Prevention of Communicable Diseases (Y)

Based on Figure 2, the analysis above shows that the condition of the behavior in the prevention of infectious 
diseases in the category of very low percentage obtained by $2 \%$ ( 4 of the 200 total respondents), the lower categories the percentage obtained by $19.50 \%$ (39 of the 200 total respondents), the category of being obtained percentage of $55.50 \%$ (111 of the 200 total respondents), the percentage of high category obtained $21.50 \%$ ( 43 of the 200 total respondents) and the very high category sebasar obtained percentage to $1.50 \%$ ( 3 of the 200 total respondents). From these results it can be concluded in the majority of respondents were in the interval score 75-98 with category.

\subsection{Communicable Disease Prevention Knowledge (XI)}

Based on figure 3, the analysis above shows that the condition of infectious disease prevention knowledge in the low category the percentage obtained by 11.00 (22\% of the 200 total respondents), while in the high category obtained a percentage of $89.00 \%$ (178 of the 200 total respondents). From these results it can be concluded in the majority of respondents were in the interval score 16-31 with a high category.

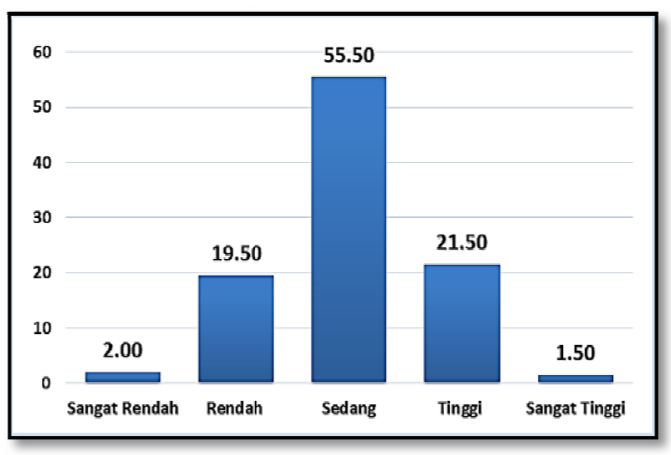

Figure 2. Distribution of respondents by variable data behavioral prevention of infectious diseases

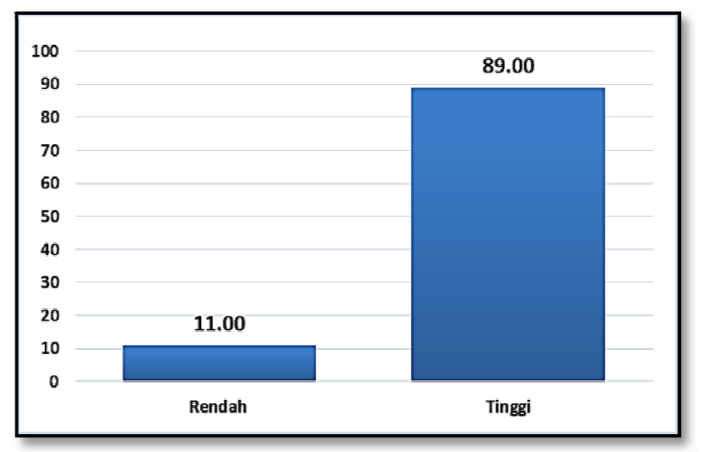

Figure 3. Distribution of respondents by variable data communicable disease prevention knowledge

\subsection{Knowledge Behavior Clean and Healthy (X2)}

Based on Figure 4, the analysis above shows that the conditions of knowledge of clean and healthy behavior in the low category the percentage obtained by 5.50 ( $11 \%$ of the 200 total respondents), while in the high category obtained a percentage of $95.50 \%$ ( 189 of the 200 total respondents). From these results it can be concluded in the majority of respondents were in the interval score 11-23 with a high category.

\subsection{Motivation Prevention of Communicable Diseases (X3)}

Based on Figure 5, the analysis above shows that the conditions for the prevention of infectious diseases motivation at a very low category obtained a percentage of $0.00 \%$ ( 0 of 200 total respondents), the low category obtained percentage $0.00 \%$ ( 0 of 200 total respondents), the categories were obtained percentage deari $18.00 \%$ (36 of 200 total respondents); high category obtained a percentage of $79.00 \%$ (158 of 200 total respondents), and the category of very high percentage obtained of 3.00 ( $6 \%$ of 200 total responden). From these results it can be concluded that in general the respondents have a high motivation category and are at intervals Score 89-109. 


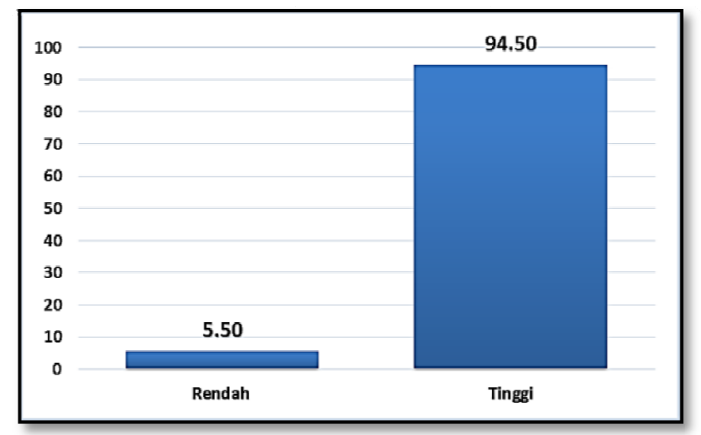

Figure 4. Distribution of respondents by variable data knowledge behavior clean and health

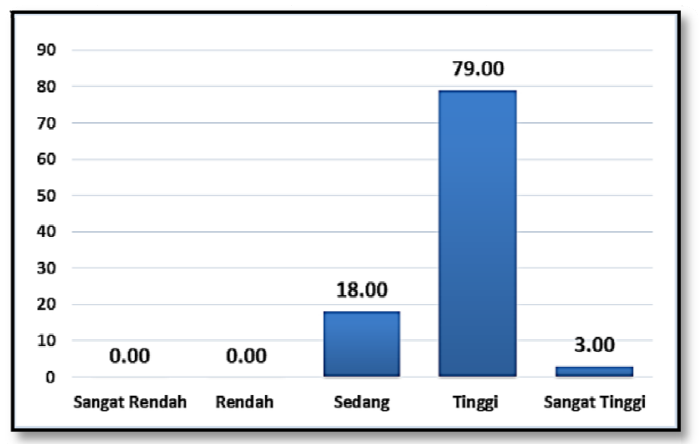

Figure 5. Distribution of respondents by variable data motivation prevention of infectious diseases

\subsection{Attitude Prevention of Communicable Diseases (X4)}

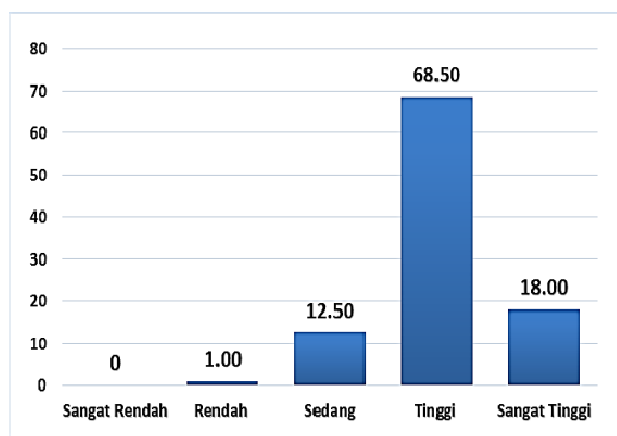

Figure 6. Distribution of respondents by variable data disease infectious prevention attitude

Based on the analysis above shows that the conditions for the prevention of infectious diseases attitude at very low category obtained a percentage of $0.00 \%$ ( 0 of the 200 total respondents), the low category percentages obtained were $1.00 \%$ ( 2 of 200 total respondents), the category of being obtained percentages $12.50 \%$ ( 25 of 200 total respondents), the percentage of high category obtained $68.50 \%$ (137 of the 200 total respondents) and the category of very high percentage obtained sebasar $18.00 \%$ (36 of the 200 total respondents). From these results it can be concluded in the majority of respondents were in the interval Score 96-117 with high category.

\section{Result Analysis}

Based on the analysis of SEM using AMOS program 22, to determine the effect of exogenous variables on the endogenous variables as follows: 
Table 1. Results of regression weights: (group number 1-default model)

\begin{tabular}{llccccc}
\hline & & Estimate & S.E. & C.R. & P & Label \\
\hline ATTITUDE $<---$ & PPHBS & -.010 & .008 & -1.196 & .232 & par_2 \\
ATTITUDE $<---~$ & PPPM & -.070 & .029 & -2.364 & .018 & par_4 \\
BEHAVIOR $<---$ & PPPM & .539 & .083 & 7.111 & $* * *$ & par_1 \\
BEHAVIOR <--- & ATTITUDE & -.160 & .138 & -1.156 & .247 & par_3 \\
BEHAVIOR <--- & MOTIVATION & -.020 & .088 & -.225 & .822 & par_5 \\
BEHAVIOR <--- & PPHBS & .013 & .012 & 1.110 & .267 & par_16 \\
\hline
\end{tabular}

Table 2. Standardized regression weights: (group number 1-default model)

\begin{tabular}{lll}
\hline & & Estimate \\
\hline ATTITUDE $<---$ & PPHBS & -.092 \\
ATTITUDE $<---$ & PPPM & -.226 \\
BEHAVIOR $<---$ & PPPM & .877 \\
BEHAVIOR $<---$ & ATTITUDE & -.073 \\
BEHAVIOR $<---$ & MOTIVATION & -.013 \\
PERILAKU $<---$ & PPHBS & .058 \\
\hline
\end{tabular}

\subsection{Effect of Infectious Diseases Prevention Knowledge against Infectious Disease Prevention Behaviors}

Based on the results of the analysis of Table 1 and 2 above, shows the magnitude of Communicable Disease Prevention Knowledge Effect Against Infectious Disease Prevention Behavior positive for 0877 with a value of $\mathrm{CR}$ amounted to $7,111>2.56$ and a probability value (p) marked $* * *$ hypothesis $\mathrm{H} 0$ is rejected, meaning a significant difference between the knowledge of Conduct Against Infectious Disease Prevention Communicable Disease Prevention. The influence coefficient is positive, the which may indicate that the higher the level of knowledge of Communicable Disease Prevention, the more high-Behavioral Prevention of Communicable Diseases or vice versa.

\subsection{Effect of Infectious Diseases Prevention Knowledge Attitude against Infectious Disease Prevention}

Based on the results of the analysis of Tables 1 and 2 above, shows the influence of Communicable Disease Prevention Knowledge Attitude Against Infectious Disease Prevention negative for 0226 with a probability value (p) of 0.018 . With the value of $(\mathrm{p})<0.05 . \mathrm{H}_{0}$ is rejected, meaning a significant difference between Knowledge Attitude Against Infectious Disease Prevention Communicable Disease Prevention. The influence coefficient is negative the which may indicate that the higher the level of knowledge of the Communicable Disease Prevention increasingly Low Attitudes Prevention of Communicable Diseases or otherwise.

\subsection{Knowledge Influence Behavior Clean and Healthy Behavior against Infectious Disease Prevention}

Based on the results of the analysis of Tables 1 and 2 above, shows the influence of Knowledge Behavior Clean and Healthy for Infectious Disease Prevention Behavior positive for 0058 with a probability value (p) of 0.267. With the value of $(\mathrm{p})>0.05 . \mathrm{H}_{0}$ is accepted, meaning there is no significant influence of Knowledge Behavior Clean and Health Behavior Against Infectious Disease Prevention. The influence coefficient is positive, which may indicate that the higher the level of Communicable Disease Prevention Behavioral Sciences, the more High-Behavioral Prevention of Infectious Diseases, or vice versa.

\subsection{Knowledge Influence Behavior Clean and Healthy Attitude against Infectious Disease Prevention}

Based on the results of the analysis of Table 1 and 2 above, shows the influence of Knowledge Behavior Clean And Healthy Attitude Against Infectious Disease Prevention negative for 0.092 with a probability value (p) of 0.232 . With the value of $(\mathrm{p})>0.05 . \mathrm{H}_{0}$ is accepted, meaning there is no significant influence of Knowledge Behavior Clean and Healthy Attitude Against Infectious Disease Prevention. The influence coefficient is negative which may indicate that the higher level of knowledge Behavior Clean and Health Low-attitude then 
the Communicable Disease Prevention or otherwise.

\subsection{Motivation Influence Behavior against Infectious Disease Prevention Communicable Disease Prevention}

Based on the results of the analysis of Table 1 and 2 show the influence of Communicable Disease Prevention Motivation Against Infectious Disease Prevention Behaviors of negative 0.013 with probability (p) of 0.822 . With the value of $(p)>0.05 . \mathrm{H}_{0}$ is accepted, meaning there is no significant influence of motivation on the Prevention of Infectious Diseases Infectious Disease Prevention Behaviors. The influence coefficient is negative which may indicate that higher levels of motivation Prevention of Infectious Diseases, the lower the Communicable Disease Prevention Behaviors or otherwise.

\section{Discussion}

\subsection{Effect of Infectious Diseases Prevention Knowledge of the Communicable Disease Prevention Behaviors}

Based on the results of the study showed that there is a significant relationship between knowledge of the Communicable Disease Prevention Communicable Disease Prevention Behaviors. The influence coefficient is positive, which may indicate that the higher the level of knowledge of Communicable Disease Prevention higher level of Behavioral Prevention of Infectious Diseases. Communicable Disease Prevention Behavioral variables are defined in this study is the activity or acts committed by public Maros associated with source control measures of disease, the cause of disease control measures, and increase the body's resistance to infectious diseases Tb, diarrhea, and dengue, while Knowledge Communicable Disease Prevention is all factual knowledge, conceptual and procedural known by the public Maros associated with source control of infectious diseases, control of the causes of infectious diseases, and increase endurance tehadap Tb infectious diseases, diarrhea, and dengue.

In connection with the role of knowledge has a positive influence on behavior, this is in line with the theory Bannet in Swan and Stepp (1979) which states that the environmental behavior is an action or individual action based on the knowledge, attitudes and values espoused. So the behavior of infectious disease prevention district's society is also based on the knowledge of infectious disease prevention that has been owned obtained from health education or health promotion. Furthermore, the results of this study in accordance with Asriani (2011) study which states that knowledge relating to compliance tuberculosis in pulmonary tuberculosis treatment program in PHC Example Medan.

From the above it can be concluded that in order to improve the district's public behavior in the prevention of infectious diseases that can be done is to increase factual knowledge, conceptual, and procedural about infectious diseases through the role of health workers in community empowerment in health through keseahatan education or health promotion.

\subsection{Effect of Infectious Diseases Prevention Knowledge of the Attitude of Communicable Disease Prevention}

Based on the results of the study showed that there is a significant relationship between knowledge of the attitude of Communicable Disease Prevention Communicable Disease Prevention. Kofesien effect is negative this attitude identifies that the higher the lower the district's community Behavior Communicable Disease Prevention or otherwise. Communicable Disease Prevention attitude variables are referred to in this research is the tendency to respond (positively or negatively) by Maros Regency society associated with the source of disease control measures, control measures that cause disease, and increase the body's resistance to infectious diseases $\mathrm{Tb}$, diarrhea, and DHF.

In connection with the role of knowledge that have an influence on attitude, this is in line with the opinions Sarwono (2007), which states that a person's attitude can be changed by obtaining additional information about the object, through persuasion and pressure of the environment. The information referred to in this opinion is knowledge about the prevention of infectious diseases in the form of factual, conceptual, and procedural about source control infectious diseases, control of the causes of infectious diseases, and increase endurance, especially $\mathrm{Tb}$ tehadap infectious diseases, diarrhea, and dengue. Furthermore, Azwar (2003), states that the knowledge memengang important role in determining the attitude. Information received will increase the person's knowledge. Knowledge that will raise awareness in the form of an attitude.

From the above it can be concluded that in order to change the attitude of district's community in the prevention of infectious diseases is necessary to increase knowledge about the prevention of infectious diseases and the necessary regulation of the government so that people can be healthy. 


\subsection{Knowledge Influence Behavior Clean and Healthy Behavior Influential against Infectious Disease Prevention}

Based on the results of the study indicate that there is no significant influence of PHBs Knowledge Against Infectious Disease Prevention Behaviors. The coefficient of the positive influence that means that PHBs knowledge indicates that the higher the level the more High PHBs Knowledge also Communicable Disease Prevention Behaviors or otherwise. Variable knowledge PHBs are referred to in this research is to use knowledge of basic sanitation, healthy home inhabit knowledge, knowledge of a balanced diet, water quality knowledge, and knowledge to protect themselves from disease-based environment.

In connection with the role of the community's knowledge PHBs Maros against infectious disease prevention behavior, not in line with the results Wahyuni (2008), which states that the determinant of knowledge, attitude, level of education, population density, and home ventilation affect the behavior of people in prevention TB disease transmission.

From the above description, it can be concluded that in order to change people's behavior Maros in infectious disease prevention, health promotion needs to be done continuously so that people can grow awareness of the importance of PHBs in maintaining health.

\subsection{Knowledge Influence Behavior Clean and Healthy for Infectious Disease Prevention Attitude}

Based on the results of the study indicate that there is no significant influence of PHBs Knowledge Attitude Against Infectious Disease Prevention. The coefficient of negative influences which means that the district's knowledge society PHBs indicated that higher levels of knowledge PHBs then lower the Communicable Disease Prevention attitude or vice versa. Communicable Disease Prevention attitude variables are referred to in this research is the tendency to respond (positively or negatively) by Maros Regency society associated with the source of disease control measures, control measures that cause disease, and increase the body's resistance to infectious diseases $\mathrm{Tb}$, diarrhea, and DHF, while PHBs Knowledge is all factual knowledge, conceptual and procedural associated with the use of basic sanitation, healthy home inhabit knowledge, knowledge of a balanced diet, water quality knowledge, and knowledge to protect themselves from disease-based environment.

In connection with the role of PHBs knowledge of the attitudes of society in the prevention of infectious diseases in this study, is not in line with the opinions Sarwono (2007), which states that a person's attitude can be changed by obtaining additional information about the object, through persuasion and pressure of the environment. The information referred to in this opinion is knowledge of PHBs. Furthermore, Anwar (2003), states that the knowledge memengang important role in determining the attitude. Information received will increase the person's knowledge. Knowledge that will raise awareness in the form of an attitude. This is caused by a factor of public education in general are at a low category, so the ability for understanding PHBs limited knowledge society consequently not determine the attitude in the prevention of infectious diseases.

From the above description, it can be concluded that in order to change attitudes masyarakata in the prevention of infectious diseases associated with knowledge PHBs, efforts should be made in the form of health education or promotion continuously.

\subsection{Influence Motivation to Behavior Prevention of Infectious Diseases Prevention of Infectious Diseases.}

Based on the results of the study indicate that there is no significant influence of motivation Behavior Against Infectious Disease Prevention Communicable Disease Prevention. The coefficient of the negative influence that indicates that the higher level of knowledge of Communicable Disease Prevention, the higher the Communicable Disease Prevention Behaviors or otherwise. Communicable Disease Prevention Motivation variable in question in this research is a force something that is in someone who can push, turn, move and direct the actions undertaken by the public Maros associated with source control measures of disease, the cause of disease control measures, and increased resistance to infectious diseases $\mathrm{Tb}$, diarrhea, and dengue, while the Communicable Disease Prevention Knowledge is all factual knowledge, conceptual and procedural Maros known by the public relating to the control of infectious diseases sources, controlling the causes of infectious diseases, and increase endurance Cosmos $\mathrm{Tb}$ infectious diseases, diarrhea, and dengue.

In connection with the role of motivation on behavior prevention of infectious diseases mentioned above, is not in line with the opinions Stooner (1992), which states that motivation is something that causes and supporting actions or behavior. This, due to the district's because people do not feel that prevention of infectious diseases is a necessity, Sarwono (2007). From the above description, it can be concluded that in order to improve the district's public behavior in the prevention of infectious diseases it is necessary to increase the motivation of infectious disease prevention through the provision of health care facilities, health workers fairly, environmental 
sanita facilities such as clean water, public toilets, landfills garbage and so on.

\subsection{Direct Impact, Influence of Indirect and Total Effect}

Table 3. Results of Direct Impact Analysis, Indirect Influence, and Impact Total

\begin{tabular}{lllll}
\hline \multicolumn{1}{c}{ Variabel } & & $\begin{array}{l}\text { Direct } \\
\text { Influence }\end{array}$ & Indirect Influence & Total Influence \\
\hline Behavior PPPM & $\longleftarrow$ & 0.877 & 0.016 & 0.893 \\
Attitude PPPM & $\longleftarrow$ & -0.226 & 0 & -0.226 \\
Behavior Attitude & $\longleftarrow$ & -0.073 & 0 & -0.073 \\
Behavior PPHBS & $\longleftarrow$ & 0.058 & 0.007 & 0.065 \\
Attitude PPHBS & $\longleftarrow$ & -0.092 & 0 & -0.092 \\
Behavior Motivation & $\longleftarrow$ & -0.013 & 0 & -0.013 \\
Attitude Motivation & $\longleftarrow$ & 0.000 & 0 & 0.000 \\
\hline
\end{tabular}

Source: Results of Data Processing 2014.

From the analysis of Table 3 above, it has been proved that each lane exogenous variables on the endogenous variables tested the influence of direct, indirect, and total effect, showed that:

- Communicable Disease Prevention Knowledge variables directly affect positive for 0.877 ; indirect positive effect of 0016; and the total effect of the positive. 0.893 to the Communicable Disease Prevention Behavior.

- Knowledge Variable Clean and Healthy Lifestyle (PHBs) direct effect of positive 0058; indirect positive effect of 0.007; and the total effect of positive 0006 for Infectious Disease Prevention Behaviors.

- Variable Motivation Against Infectious Disease Prevention Communicable Disease Prevention Behaviors of Negative 0.013 .

Based on differences in the magnitude of the effect of exogenous variables Communicable Disease Prevention Behavioral variables can be concluded that the Communicable Disease Prevention Knowledge variables most dominant compared to the PHBs veriabel, Motivation, and Attitude. That is to change behavior is becoming behavior can prevent the transmission of infectious diseases so that the incidence of infectious diseases can be suppressed in the district's community, then that needs to be improved first is knowledge about the prevention of infectious diseases, further PHBs, then the attitude of Communicable Disease Prevention, and the last Motivation Prevention Infectious diseases in general and in particular to the infectious disease tuberculosis, dengue fever, and diarrhea.

\section{Conclusion}

The level of knowledge of Communicable Disease Prevention district's society shows that of the 200 respondents who had pengetahaun low category as many as 22 people $(11.0 \%)$ and higher category $178(89.0 \%)$. It was concluded that knowledge of infectious disease prevention majority district's public high category. The level of knowledge of Clean and Healthy Lifestyle (PHBs) district's community shows that of the 200 respondents who had knowledge of the low category as many as 11 people $(5.5 \%)$ and the high category of 189 people (94.55). It was concluded that knowledge of clean and healthy communities majority district's high category. The level of Communicable Disease Prevention Attitude district's society shows that of the 200 respondents who have the attitude category Whereas many as 25 people $(12.5 \%)$, high category as many as 137 people $(68.5 \%)$, and very high category as many as 36 people $(18.0 \%)$. It can be concluded that the attitude of infectious disease prevention majority district's public high category. Knowledge of infectious diseases affect the behavior of people in the prevention of infectious diseases in Maros, It is based on the value of CR $7.111< \pm$ 2:56, and the value of $(\mathrm{p})$ marked $* * * *$ at significance level of $0.05(5 \%)$. This means that knowledge of infectious diseases, especially $\mathrm{Tb}$, diarrhea and dengue can improve people's behavior in terms of prevention of infectious diseases.

Knowledge of infectious diseases affect the attitude of infectious disease prevention in the district's community. It is based on the value (p) $0.0188<0.05$, significant at the 0.05 level $(5 \%)$. This means that knowledge of 
infectious diseases, especially $\mathrm{Tb}$, diarrhea and dengue can increase people's attitudes in terms of prevention of infectious diseases. Knowledge Behavior Clean and Healthy does not affect the behavior of people in the prevention of infectious diseases in Maros. It is based on the value (p) $0.267>0.05$ at significance level of 0.05 (5\%). This means that knowledge PHBs can not improve people's behavior in terms of prevention of infectious diseases. Knowledge of clean and healthy does not affect the attitude of the community in the prevention of infectious diseases in Maros. It is bas ed on the value (p) of $0.232>0.05$ at significance level of $0.05(5 \%)$. This means that knowledge PHBs can not improve people's behavior in terms of prevention of infectious diseases.

\section{References}

Asriani, Y., \& Isnanda, C. D. (2011). Knowledge relationship with Compliance Tuberculosis Patients in Treatment of Tuberculosis Program in Health Center Terrain Model.

Azwar, S. (2003). Human Attitude Theory and Measurement. Pustaka Pelajar Offset. Jakarta.

Depkes, R. I. (2010). Law of Health.

District Health Office Maros. (2012). Health Profile Maros. Retrieved from http://marossehat.blogspot.com/p/maros.html

Media, Y. (2012). Knowledge, Attitude and Behavior Society bekaitan With Disease (Tb) in the Lung Health Center Katik Koto Padangpanjang (Sumatera Barat).

Notoatmodjo, S. (2007). Health Promotion and Behavioral Sciences. Jakarta. Rineka Cipta.

Nurjanah, Arsin, A., \& Ansariadi. (2008). Relations Practice PSN and Water Access with dengue incidence in Elementary Students in the District of South Palu.

Sarwono, S. (1993). Sociology of Health. Yogyakarta, Gadjah Mada University Press.

South Sulawesi Provincial Health Office. (2010). Health Profile of South Sulawesi Province.

Wahyuni. (2008). Behavioral Determinants of Civil Society in the Prevention of Disease Transmission of tuberculosis in Puskesmas Bendosari. Gaster, 4(1), 178-183. Surakarta. Diakses.

\section{Copyrights}

Copyright for this article is retained by the author(s), with first publication rights granted to the journal.

This is an open-access article distributed under the terms and conditions of the Creative Commons Attribution license (http://creativecommons.org/licenses/by/3.0/). 